5. Young people up to 14 years of age should be admitted to a paediatric ward rather than to a general surgical or medical ward. Older children should ideally be admitted to an adolescent medical ward, if this is available.

6. Hospital staff are responsible for making contact with the parents or guardian of the young person in order to seek their participation in a psychiatric assessment, and for alerting the child psychiatric team.

7. The deployment of the child psychiatric team is a matter for the individual child psychiatrist concerned. Responsibility lies primarily with the psychiatrist who may decide to delegate that responsibility to others if he so wishes.

8. The child psychiatric team may ofier follow-up directly, or be available for consultation to other professionals undertaking this. Where an adolescent is unable to return home because of a disrupted family situation, it will then be the responsibility of the Social Services Department to provide an alternative placement.

9 .If an adolescent is judged to be too psychiatrically disturbed to be discharged home, then in-patient treatment may be needed in a psychiatric unit catering for the appropriate age range.

\section{REFERENCES}

BLACK, D. \& Pond, D. A. (1980) After the suicide attempt. Lancet, ii, 867-68.

Catalan, J., Marsack, P., hawton, K., Whitwell, D., Fagg, J. \& BANCROFT, J. (1981) Comparison of doctors and nurses in the assessment of deliberate self-poisoning patients. Psychological Medicine, 10, 483-91.

Central and Scotrish Health Services Councis (1968) Hospital Treatment of Acute Poisoning. London: HMSO.

GArDNer, R., HANKA, R., Evison, B., MOUNTFORD, P. M. O'BrIEN, V. C. \& RoberTs, S. J. (t) fl( Consultation-liaison scheme for self-poisoned patients in a general hospital. British Medical Journal, in, 1392-94.

HAWTON, K., GATH, D. \& SMTrH, E. (1979) Management of attempted suicide in Oxford. British Medical Journal, it, $1040-42$.

\& GOLDACRE, M. (1982) Hospital admissions for adverse effects of medicinal agents (mainly self-poisoning) among adolescents in the Oxford Region. British Journal of Psychiatry, 141, 166-70.

O'Grady, J., OsBorn, M. \& Cole, D. (1982a) Adolescents who take overdoses: Their characteristics, problems and contact with helping agencies. British Journal of Psychiatry, 140, 118-23.

- OsBorn, M., O'Grady, J. \& Cole, D. (1982b) Classification of adolescents who take overdoses. British Journal of Psychiatry, 140, 124-31.

MnISTRY OF HeAlth (1961) National Health Senvice: Attempted Suicide. HM Circular (61) 94. London: HMSO.

Newson-SMrth, J. \& Hirsch, S. (1979) A comparison of social workers and psychiatrists in evaluating parasuicide. British Journal of Psychiatry, 134, 335-42.

Royal College of Psychiatrists (1976) Memorandum on the psychiatry of adolescence. British Journal of Psychiatry. News and Notes, September, 6-9.

\title{
Spring Quarterly Meeting, 1982
}

The Spring Quarterly Meeting was held at the Holiday Inn, Liverpool and the University of Liverpool on 20 and 21 April 1982 under the Presidency of Professor Kenneth Rawnsley.

\section{Scientific Meetings}

Twesday 20 April

The Manchester Psychotherapy Project

The conversational model-Dr R. F. Hobson

Clarification of this model-Prof D. P. Goldberg

Teaching this model to trainees-Dr F. Margison

Evaluation of the training - Dr G. P. Maguire

The Role of Nurses in Liaison Psychiatry

Management of patients who have attempted suicide-Dr K. Hawton

Monitoring of progress in mastectomy patients by specialist nurses-Dr G. P. Maguire

Training community nurses and health visitors to assess psychosocial adjustment in mastectomy patients-Mrs Ann Faulkner

Screening and counselling of medical in-patients for alcohol problems-Drs G. Lloyd, J. Chick and Ms E. Crombie

Psychosomatic disorders in children-Dr Phillip Pinkerton

\section{Wedneeday 21 April: Morning Session A}

Psychiatric Disorder in the Elderly

Normal effects of ageing on language-Prof Denis Bromley

The relationship of level of activity to depression in a day centre for the elderly-Ms Ann Davies

A community survey of psychiatric illness in an elderly population in London-Prof J. R. M. Copeland

Normal polycythaemia in arteriosclerotic dementia-Dr $\mathbf{R}$. M. Philpott

Morning Sescion B

General Topics

Growth hormone responses to apomorphine: Type 1 
symptoms in schizophrenia-Prof Jock Cleghorn

Life events and mania-Dr Sidney Kennedy

Mental health in Aborigines-Dr John Spencer

Thiamine, riboflavine and pyridoxine in mental illness- $\mathrm{Dr}$ M. W. P. Carney

Menorrhagia and depression-Dr Maurice Greenberg

\section{Afternoon Seasion A}

Forensic Psychiatry

Britain's sadistic murder syndrome: A review of patients at Park Lane Hospital with special reference to prediction of dangerousness-Dr M. MacCulloch

Survey of patients from the Mersey RHA now in Special Hospitals-Dr J. Higgins

A comparison between the first five years' experience of two interim secure units (North Western RHA and Mersey RHA)—Dr Angus Campbell

Afternoon Session B

New Approaches to the Care and Assessment of the Mentally Handicapped

The use of the hospital as a resource centre for mental handicap-Dr Yvonne Wiley

The Gloucestershire Project: A community mental handicap service-Dr Jack Bavin

The evaluation of assessment-Dr Elaine Wright

The rehabilitation process in mental handicap-Dr Lauchlan Campbell and Mr Peter McGill

\section{Business Meeting}

The Business Meeting was held on Wednesday 21 April 1982.

\section{Minutes}

The Minutes of the previous meeting held on 10 February 1982 at Charing Cross Hospital Medical School (Bulletin, April 1982, 6, 71) were approved and signed as a correct record.

\section{Obituary}

The Registrar announced with regret the deaths of the following members:

Diana Boviu, formerly Consultant Psychiatrist, Burnley General Hospital, Burnley, Lancs.

Nihal Chandy Chacko, Lecturer in Psychiatry, Department of Psychological Medicine, Faculty of Medicine, University of Malaya, Kuala Lumpur, Malaysia.

HUBBert ARChIBald Cole, formerly Consultant Psychiatrist, Rauceby Hospital, Sleaford, Lincs.

\section{Election of Honorary Fellows}

The following were approved for election to the Honorary Fellowship:
Sir Douglas Black, President of the Royal College of Physicians; formerly Professor of Medicine, Manchester University and Chief Scientist at the Department of Health and Social Security.

DR DAVIm L. Davies, formerly Dean of the Institute of Psychiatry and Physician, Bethlem Royal and Maudsley Hospitals.

Professor Max hammton, Emeritus Professor of Psychiatry, University of Leeds School of Medicine; Honorary Clinical Professor of Psychiatry, University of Missouri-Columbia; President of the British Academy of Psychopharmacology.

Professor Robert O. Jones, formerly President of the Canadian Psychiatric Association; President of the Canadian Medical Association; Vice-President of the American Psychiatric Association; Professor of Psychiatry at Dalhousie University.

Professor Sir Desmond Pond, Chief Scientist at the Department of Health and Social Security; formerly President of the Royal College of Psychiatrists and Professor of Psychiatry, London Hospital.

\section{Registrar's Report}

Professor Gerald Tmmbury presented the Registrar's report:

'The period since my last report on 10 February 1982 has been a particularly busy one for the College. Council held a Special Meeting on 12 March in addition to its normal meeting on 18 March. The Executive and Finance Committee has met twice and there have been meetings of the Regional Advisers and of the Secretaries of Divisions and Sections.

'The main business of the Council Special Meeting was to discuss the present progress of the Mental Health (Amendment) Bill. Council felt that the current proposals to require a medical second opinion for the administration of medication to detained patients except in emergencies was impracticable and would pose considerable problems for all psychiatrists, particularly those working in the Special Hospitals. The President has subsequently sent a letter to all Members about this and the College will be attempting to influence Parliament to produce the desirable amendments to the Bill. The President will be meeting the Special Standing Committee of the House of Commons on 27 April.

'Council approved a report from the Public Policy Committee on a DHSS consultation document on the training of Approved Social Workers who are required by the new Mental Health legislation. The College has recommended that where local arrangements are made for the training and approval of Social Workers there should be involvement of psychiatrists and psychiatric services.

'The Special Meeting to an invited audience was held on 8 March to discuss the problem of the Sick Doctor. The 
meeting was sponsored by the College and the Association of Anaesthetists and was attended by representatives of all Colleges and Faculties, the General Medical Council, the DHSS, the Medical Defence Unions and other interested parties. A report of this meeting will appear in due course. Meanwhile, the College will continue to have discussions with certain Colleges and other bodies in an effort to provide a speedy and confidential service to help doctors who are in difficulties because of psychiatric illness.

'At the meeting of the Regional Advisers on 22 March there was further discussion about the involvement of Regional Advisers in the work of the College Divisions and it was agreed that the role of Regional Advisers should be extended so as to involve them in the development of rotational training programmes in Regions, and where practicable, in co-ordinating the activities of psychiatric tutors in the Regions. It was also agreed that Regional Advisers would, wherever possible, represent the College on Appointment Committees for Senior Registrars [Bulletin, August $1982,6,145-46]$.

'A Special Committee has been set up to consider the College's response to the Short Report and the Government's reaction to that report. The Special Committee is collecting information about the manpower and training implications for psychiatry of the proposal to increase the number of consultants and reduce the number of junior doctors. The Special Committee's comments will be reported in due course.

'The Special Committee which is considering the College's response to the Research Report on the use of ECT met on 22 February. Among other matters discussed, it was agreed to encourage Divisions of the College to consider holding meetings of consultants who would take a particular interest in the administration of ECT in their hospitals and units, and it was made known that Dr John Pippard, who conducted the Research Project, would be willing to visit the Divisions in order to discuss the appropriate methods of administering ECT and ways in which improvements could be achieved. A poster entitled "How to Give ECT" has been prepared and is being distributed.

'The House Committee continues to arrange for the refurbishment of 17 Belgrave Square and work is now in progress to redecorate and improve the Members' room on the ground floor and to provide an additional Lecture Room.

'In conjunction with the Association of University Teachers of Psychiatry and the Association of Psychiatrists in Training, the College participated in a successful weekend conference in Cambridge from 26 to 28 March on training and recruitment in psychiatry. A report of this conference will be published in due course [Bulletin, June 1982, 6, 105; 107].

'The Finance Committee has approved the grant of a sum of $£ 2,500$ to the Research Committee in order to carry out a prospective study of the careers of women psychiatrists. This study will be undertaken by Dr Audrey Ward of the Medical Care Research Unit at the University of Sheffield.

'Finally, may I thank Dr David Enoch, Professor Copeland, Dr Cookson and Dr Ansari and all of our colleagues and friends in Liverpool for the arrangements which they have made for this very successful Quarterly Meeting.'

\section{A need for a Research Register?}

The College ECT survey questionnaire in March 1980 asked 'Are you doing research on any aspect of the use of ECT?' From the 61 who replied 'yes', it appears that there were 49 separate individuals or groups involved. By April 1982 I knew that 12 of these had published, or had had accepted, at least some of their work. A short questionnaire was sent to the other 37 to find out how their work was going on and to canvass opinion on the possible usefulness of the College setting up a Register of Research.

Of the 37 questioned, one had died and nine did not reply. Of the 27 (73 per cent) who replied, seven had completed and published their work and six others had published some of their work. Eight were continuing research on ECT but had not yet reported. Six had discontinued without publishing, usually because they could not find enough time or money or enlist the support and help of colleagues or assistants.

Only three would not have found a Register useful, two were doubtful and 20 thought it would have been helpful. All the 25 who answered the question were agreeable to the inclusion in a Register of their names, addresses and details of projects.

Research projects in ECT which were started after 1980 have not been considered. The amount of work in this one small area of enquiry is surprisingly large. Half of the 49 individuals or groups are known to have reported their work and others will be doing so.

These findings may encourage the Research Committee of the College to undertake the considerable task of setting up and maintaining an up-to-date Register of all psychiatric research.

John Pippard 